\title{
Zoonotic parasites of dromedary camels: so important, so ignored
}

\author{
Alireza Sazmand ${ }^{1 *}$ (D) Anja Joachim² and Domenico Otranto ${ }^{1,3}$
}

\begin{abstract}
With a global population of about 35 million in 47 countries, dromedary camels play a crucial role in the economy of many marginal, desert areas of the world where they survive under harsh conditions. Nonetheless, there is scarce knowledge regarding camels' parasite fauna which can reduce their milk and meat productions. In addition, only scattered information is available about zoonotic parasites transmitted to humans via contamination (e.g. Cryptosporidium spp., Giardia duodenalis, Balantidium coli, Blastocystis spp. and Enterocytozoon bieneusi), as foodborne infections (e.g. Toxoplasma gondii, Trichinella spp. and Linguatula serrata) or by arthropod vectors (Trypanosoma spp.). Herein, we draw attention of the scientific community and health policy-making organizations to the role camels play in the epidemiology of parasitic zoonotic diseases also in the view of an increase in their farming in desert areas worldwide.
\end{abstract}

Keywords: Camelus dromedarius, Zoonoses, One-Health

\section{Background}

With a worldwide population of about 35 million, camels are an important source of meat and milk in many regions of the world, mainly in Africa and Asia [1]. The one-humped camel, also known as dromedary (Camelus dromedarius), account for approximately $95 \%$ of the whole population of Old World Camels and are distributed in 47 countries [1], playing a crucial role in their economy. Therefore, as they are important food sources in semi-arid and arid zones the picture of dromedaries transformed from "ship of the desert" to a "food security livestock" species. The total population of the Old World Camels (OWCs) increased by about 82\% from 19 million in 1997 to 35 million in 2017 [1], and the camel industry is in transition from nomadism to intensive production. Although this trend recognizes the economic value of this livestock species as a food source, it could also make camels an increasingly important source for zoonotic

*Correspondence: alireza.sazmand@basu.ac.ir

1 Department of Pathobiology, Faculty of Veterinary Science, Bu-Ali Sina University, Hamedan 6517658978, Iran

Full list of author information is available at the end of the article disease transmission to humans, especially in resourcepoor communities with improper sanitation and medical access. This article reviews the current knowledge on zoonotic parasites reported from camels and gaps on the topic that should be addressed in future research.

\section{What are camels and why they are important?}

The word 'camel' refers to any of the members of the family Camelidae including Old World Camels (OWC) and New World Camels (syn. South American camelids, NWC) [2]. The origin of the OWC traces back to around 40 million years ago when the first ancestors of the camelid family were found in North America before migrating via the Bering Land Bridge to the eastern hemisphere (the "Old World") [3] (Table 1). Compared with other animal species (e.g. dogs), the domestication of the dromedary camel took place rather late in human history, approximately 3000 years ago [4]. The dromedary camel is specifically adapted to life in hot, arid areas of the world, notably the Middle East, Africa and India, with a considerable feral population in Australia [5]. Unique physiological peculiarities of dromedaries in circulatory system, respiratory system, water economy mechanism,

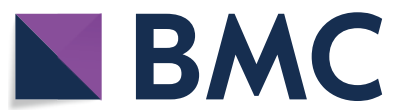

(c) The Author(s) 2019. This article is licensed under a Creative Commons Attribution 4.0 International License, which permits use, sharing, adaptation, distribution and reproduction in any medium or format, as long as you give appropriate credit to the original author(s) and the source, provide a link to the Creative Commons licence, and indicate if changes were made. The images or other third party material in this article are included in the article's Creative Commons licence, unless indicated otherwise in a credit line to the material. If material is not included in the article's Creative Commons licence and your intended use is not permitted by statutory regulation or exceeds the permitted use, you will need to obtain permission directly from the copyright holder. To view a copy of this licence, visit http://creativeco mmons.org/licenses/by/4.0/. The Creative Commons Public Domain Dedication waiver (http://creativecommons.org/publicdomain/ zero/1.0/) applies to the data made available in this article, unless otherwise stated in a credit line to the data. 
Table 1 Taxonomic classification of camelids and other artiodactylids [2]

\begin{tabular}{lll}
\hline Taxonomic rank & Scientific name & Common name \\
\hline Order & Cetartiodactyla & \\
Suborder & Tylopoda & \\
Family & Camelidae & \\
Subfamily & Camelini (Old World camelids) & \\
Genus & Camelus & \\
Species & Camelus dromedarius & Dromedary camel \\
& Camelus bactrianus & Bactrian camel \\
& Camelus bactrianus ferus & Wild Bactrian camel \\
Subfamily & Lamini (New World camelids) & \\
Genus & Lama & \\
Species & Lamaglama & Llama \\
& Lamaguanacoe & Guanaco \\
Genus & Vicugna & Alpaca \\
Species & Vicugna pacos & Vicuña \\
& Vicugna vicugna & Peruvian vicuña \\
Subspecies & V.vicugna mensalis & Argentinean vicuña \\
& V.vicugna vicugna &
\end{tabular}

heat tolerance, etc. enable them to survive almost one week with little or no food and water [6], making them suitable also for trade and trafficking over longer distances in arid areas. Indeed, they are utilized since ancient times for transportation of people, goods, warfare and as draft animals including in agriculture and in local industry. Furthermore, they provide food (meat and dairy products) with great nutritional value, wool and leather in regions of the globe where the common ruminant livestock species (cattle, sheep and goat) cannot be used for this purpose. In the year 2017, camels produced $2,852,213$ tons of milk and 630,210 tons of meat [1]. In this article "camel" refers only to "dromedary camel".

\section{Zoonoses parasites of camels}

About $65 \%$ of the articles on zoonotic pathogens of camels published between 1970 and 2018 focused on Middle East respiratory syndrome (MERS), hydatidosis, brucellosis and Rift Valley fever [7]. Camel echinococcosis is the most studied zoonotic parasitic infection affecting humans but Toxoplasma gondii, Cryptosporidium spp., Fasciola spp., Trichinella spp. and Linguatula serrata originating from camels are also considered as major public health risks [7]. Relatively few parasites of camels are specific for this host species [8], whereas many others that infect camels are (i) non-zoonotic but with a large host range; or (ii) of zoonotic concern. Transmission of zoonotic parasites includes different routes of infection such as faecal contamination (e.g. Cryptosporidium spp., Giardia duodenalis, Balantidium coli, Blastocystis spp.,
Enterocytozoon spp.), or consumption of raw or undercooked infected tissues and milk (e.g. Toxoplasma gondii, Trichinella spp., Linguatula serrata).

In addition, camels serve as reservoir hosts for Trypanosoma evansi, or may be infected by gastropod-borne trematodes (e.g. Fasciola spp., Dicrocoelium dendriticum and Schistosoma spp.) or metacestode larvae of zoonotic tapeworms, such as Echinococcus granulosus (s.l.). Moreover, camels are a blood source for several haematophagous ectoparasites, such as ticks and fleas, which ultimately may transmit zoonotic viral and bacterial pathogens (e.g. Crimean-Congo hemorrhagic fever virus, Coxiella burnetii, Anaplasma spp., Rickettsia spp., Bartonella spp. and Yersinia pestis) [9]. These parasites and infections have been detected in camels in Asia and Africa while there is not much known about the parasite fauna of camels in Australia (see section "Parasites of camels in Australia" below). The current taxonomic status of the zoonotic parasites discussed in this article is shown in Table 2.

\section{Protozoan parasites in camel faeces}

A wide range of gastrointestinal protozoan parasites develop exclusively in camels [11]. Although scientific data are available about infections of camels with several species of parasites of zoonotic importance (e.g. Cryptosporidium spp., Giardia duodenalis, Blastocystis spp., B. coli, Enterocytozoon bieneusi) their impact on human health has not been confirmed in ad-hoc studies except only one documentation on zoonosis linked with camels and that is from Iran [12]. Undoubtedly, the most investigated gastrointestinal protozoan genus in camels is Cryptosporidium [13]. Cryptosporidiosis is one of the major zoonotic parasites associated with food-borne and water-borne outbreaks [14]. Of the 39 valid species and approximately 70 host-adapted Cryptosporidium genotypes (which do not yet have species names), over 20 have been identified in human patients causing asymptomatic or mild to severe gastrointestinal disease [15]. So far, C. parvum subtype IIaA17G2R1 (a common zoonotic subtype reported in humans and animals worldwide), $C$. parvum genetically related to the $C$. hominis If subtype family, C. andersoni, Cryptosporidium rat genotype IV and a novel genotype (named "camel genotype") have been confirmed in dromedary camels by PCR and sequencing $[13,16-18]$. There is only one documentation of zoonosis linked with camels from Iran where 24 of 100 people in long-term contact with camels were found infected with Cryptosporidium spp. [12]. Although C. parvum and C. andersoni identified in camels are potentially infectious for humans, no confirmed direct 
Table 2 Taxonomic status of major zoonotic parasites of camels discussed in this article as classified by Ruggiero et al. [10]

\begin{tabular}{|c|c|c|c|c|c|}
\hline Kingdom & Phylum & Class & Order & Family & Genus \\
\hline Protozoa & Euglenozoa & Kinetoplastea & Trypanosomatida & Trypanosomatidae & Trypanosoma \\
\hline Protozoa & Metamonada & Eopharyngia & Diplomonadida & Giardiidae & Giardia \\
\hline Protozoa & Microsporidia & Minisporea (=Microsporea) & Minisporida (= Minisporea) & Enterocytozoonidae & Enterocytozoon \\
\hline Chromista & Ciliophora & Litostomatea & Vestibuliferida & Balantidiidae & Balantidium \\
\hline Chromista & Miozoa & Coccidiomorphea & Eimeriida & Sarcocystidae & Toxoplasma \\
\hline Chromista & Miozoa & Gregarinomorphea & Cryptogregarida & Cryptosporidiidae & Cryptosporidium \\
\hline Chromista & Bigyra & Blastocystea & Blastocystida & Blastocystidae & Blastocystis \\
\hline Animalia & Platyhelminthes & Trematoda $^{\mathrm{a}}$ & Plagiorchiida & Fasciolidae & Fasciola \\
\hline Animalia & Platyhelminthes & Trematoda $^{a}$ & Diplostomida & Schistosomatidae & Schistosoma \\
\hline Animalia & Platyhelminthes & Cestoda ${ }^{a}$ & Cyclophyllidea & Taeniidae & Echinococcus \\
\hline Animalia & Nematoda & Dorylaimea & Trichocephalida & Trichinellidae & Trichinella \\
\hline Animalia & Arthropoda & Arachnida & Sarcoptiformes & Sarcoptidae & Sarcoptes \\
\hline Animalia & Arthropoda & Maxillopoda & Porocephalida & Linguatulidae & Linguatula \\
\hline
\end{tabular}

a Neoophora sensu Ruggiero et al. [10]

association between camels and human infections have been reported, in contrast to other livestock such as cattle [19].

Giardia infection is extremely common in both industrialised nations and developing countries, and is responsible for about 280 million human cases of diarrhoea every year [20]. Currently eight species with over 40 animal host species have been reported, of which only Giardia duodenalis infects humans [20]. There is only one report on microscopical diagnosis of Giardia cysts and trophozoites in dromedary camels [21] with no molecular-based study on the species and genotypes. Giardia duodenalis assemblages A and B are the predominant assemblages in humans, but assemblage $E$ is increasingly reported from human patients and assemblages $\mathrm{C}, \mathrm{D}$ and $\mathrm{F}$ have occasionally been identified from human patients [22]. It is predictable that camels, like other hoofed animals, are primarily infected with the zoonotic assemblage $\mathrm{E}$, but the occurrence of other assemblages could clarify the zoonotic potential of camel giardiosis.

Balantidiosis caused by B. coli is a zoonotic disease and pigs, non-human primates and humans are known as primary reservoirs [23]. Indeed, human populations living in close proximity to domestic pigs are naturally resistant and mostly without any clinical manifestation, though a case fatality rate of $30 \%$ has been reported in acute balantidiosis with intestinal perforation or fulminating haemorrhagic dysentery and shock [23]. In absence of pig raising, such as in some Middle-Eastern countries, camels play a major epidemiological role in the transmission of B. coli [24]. Because of the pleomorphism of balantidial trophozoites and the host range, taxonomy of this genus is controversial. However, as for other mammalian hosts [25] balantidia from camels, previously named Balantidium cameli [26], are now referred to as B. coli, a species causing widespread infection with infection rates of up to $23 \%$ [27]. Recent studies on the genetic diversity of Balantidium spp. and Balantidium-like cyst-forming ciliates, such as Buxtonella, suggest that genetic analyses are needed to explain the real spectrum of intestinal ciliates as the cysts are morphologically indistinguishable. Buxtonella sulcata, another ciliate with a worldwide distribution, is mainly found in the cecum of cattle but also of camels [28]. Finding of Buxtonella-like ciliates in primates opened the hypothesis that Buxtonella may also be a pathogen in humans [29], and the possible transmission from camels to humans should be further investigated.

The genus Blastocystis comprises at least 17 different ribosomal lineages or subtypes (ST1-ST17), which are arguably separate species [30]. These parasites are estimated to colonize between 1 and 2 billion people globally, with prevalence rates ranging from $5-15 \%$ to $50-100 \%$ in developed and developing countries, respectively [30, 31]. Humans become infected with ST1 to ST9; however, over $90 \%$ of reports are associated with ST1ST4 [31]. Infections of camels with Blastocystis spp. have been reported from Australia [32], Libya [33] and Egypt [34] where ST1, ST3, ST5, ST10, ST14, ST15 or a mixture of them were identified. Interestingly, camel is the host infected with the widest range of STs out of 53 species examined [33]. Three subtypes found in camels (i.e. ST1, ST3 and ST5) can infect humans, suggesting their potential role in transmitting zoonotic subtypes.

Microsporidia are diverse emerging opportunistic pathogens with 200 genera and 1500 species, 17 of which infect humans [35]. Of these, Enterocytozoon bieneusi, a ubiquitous protozoan that infects the gastrointestinal 
tract of a large number of mammals, is frequently recognized in humans [36]. Currently 474 distinctive $E$. bieneusi genotypes from 11 groups have been differentiated out of which Group 1 members are mainly identified in humans whereas others have been suspected [35]. In the only study on dromedaries, Group 6 genotype "Macaque1" and a novel genotype named "Camel-2" (related to members of the group 8 E. bieneusi genotypes "Macaque1", "KB5" and "Horse2") were identified [16]. The zoonotic potential of E. bieneusi genotypes from camels, their frequency and distribution still need to be investigated.

\section{Toxoplasma gondii in camels: what do we know?}

Due to its exceptionally wide range of warm- and coldblooded hosts, T. gondii is one of the most successful zoonotic parasites on earth [37]. Indeed, approximately $30 \%$ of the world's human population are infected with this cosmopolitan food- and water-borne parasite [38]. In the USA alone toxoplasmosis accounts for 32,700 disability-adjusted life years (DALYs) annually, being also responsible for $8 \%$ of food-borne-illnesses hospitalizations with 86,700 confirmed patients and 330 deaths $[39,40]$. Like other livestock, camels acquire T. gondii infections through ingestion of sporulated oocysts shed by cats or wild felids in the environment [41]. Antibodies against $T$. gondii in sera of dromedaries from different countries have been determined using various techniques, reporting seroprevalences as high as $67 \%$ [42, 43]. It has been estimated that $36 \%$ of camels in Africa have anti-T. gondii antibodies [44]. Moreover, T. gondii DNA has been detected in the blood of Iranian dromedaries [45]. Clinical and congenital toxoplasmosis, however, are limited to a few reports and probably underestimated in camels [46-49]. Toxoplasma gondii cysts have been isolated from camel meat [43] but predilection sites of Toxoplasma cysts have not been comprehensively investigated in this host species. The rooted habits of nomadic populations of some African and Asian communities of raw camel liver consumption [43, 50] suggest that this could represent a risk factor for infection of humans, as T. gondii is frequently isolated from the livers of domestic ruminants and horses [51]. In addition, consumption of camel milk is becoming increasingly popular in recent years because it is richer in vitamin $C$ and iron than cow's milk, with important therapeutic effects for the treatment of type 1 diabetes and reduction of allergies in children [52]. The implication of unpasteurized camel milk as a source of human toxoplasmosis [53] suggests that consuming raw milk or dairy products without pasteurization or heat treatment (e.g. Shubat) could be a risk for human health. Little is known about the genetic characteristics of $T$. gondii genotypes infecting camels.
Some surveys showed the occurrence of all three conventionally defined clonal lineages (Types I, II and III) in camel meat and milk $[18,54,55]$. All of these types have also been isolated from human patients [56]. Since the conventional nomenclature of Toxoplasma isolates does not sufficiently delineate the plethora of existing genotypes [57], multilocus PCR-RFLP genotyping should be applied to improve current understanding of the transmission dynamics of infected camels to people consuming their meat and dairy products.

\section{Trypanosoma evansi in camels}

Camels are affected by several Trypanosoma species [58]. While T. evansi, the etiologic agent of "Surra" is the more prevalent trypanosome species of camels [59], T. brucei, T. congolense and T. vivax are found at low infection rates [60, 61]. Due to a partial loss of T. evansi mitochondrial DNA, which occurred during its segregation from T. brucei [62], this species can be mechanically transmitted by virtually all biting flies, so its geographical distribution is potentially unlimited. Trypanosoma evansi affects a wide range of domestic and wild mammals in Africa, Asia and South America [63], and recent outbreaks of infection amongst dromedary populations on the Canary Islands, in mainland Spain and France demonstrated the potential of the parasite to spread rapidly even in non-endemic areas [64]. In dromedaries, the infection may cause significant morbidity and great impairment of productivity and mortality [65]. It is assumed that the spread of $T$. evansi among camels with the consequence of fatal anaemia weakened the Arab-African Muslim forces in their prolonged battle against Christendom, as they relied heavily on camels and equids for transport and economy [66]. Trypanosoma evansi has its highest prevalence in camels compared to other animal hosts such as buffaloes, cattle, dogs, equids and small ruminants [63], but in contrast to other livestock species, in camels the economic burden of this infection has not been evaluated [67]. Human cases of T. evansi infection have been reported from India, Sri Lanka, Egypt and Thailand [68-70]. For a decade it was hypothesized that human susceptibility to $T$. evansi could be linked to insufficient or missing levels of human trypanocide apolipoprotein L1 (APOL1), a trypanocidal component of normal human serum [71]. However, a recent report of infection in a patient with no previous immunological risk, 2 wild-type APOL1 alleles and a normal serum APOL1 concentration suggested that T. evansi is a true zoonosis with a risk of infection for the general population [70].

Traditionally tabanids, muscids and hippoboscids are considered to be mechanical vectors of $T$. evansi, and several species of the genera Ancala, Atylotus, Chrysops, Haematobia, Haematopota, Hippobosca, Pangonia, 
Philoliche, Stomoxys and Tabanus have been collected directly from camels or their surroundings [9, 72-74]. Stomoxys calcitrans, Stomoxys niger, Tabanus taeniola, Tabanus par and Tabanus subangustus collected on cattle have been identified to be infected with T. evansi [75]. However, there is no molecular confirmation on the role of definite fly species as vectors of T. evansi in camels.

\section{Hydatidosis in camels}

Cystic echinococcosis (CE) is a major zoonotic infection with worldwide distribution caused by the larvae of the tapeworm Echinococcus granulosus (s.l.). CE causes considerable medical costs and economic losses in endemic areas. Camels are intermediate hosts for several zoonotic Echinococcus species, being important in their epidemiology [76]. Cysts are commonly found in the lungs and, to a lesser extent, the liver of camels, resulting in carcass condemnation and, subsequently, great economic losses. In Iran where $\mathrm{CE}$ is endemic, the annual monetary burden of CE has been estimated at 232.3 million USD, out of which the loss due to condemnation of infected camel livers amounts to approximately 600,000 USD [77]. Infection of camels with cysts of E. granulosus (s.s.), E. ortleppi and E. canadensis (formerly G1, G2, G3, G5, G6) have been reported [78-80], all of them being causative agents of human CE [80]. The prevalence of Echinococcus species infecting dromedaries differs in various studies, i.e. in studies from Iran and Ethiopia the most prevalent species isolated from camels was E. granulosus [81, 82], while in Nigeria and Oman most of the isolates were identified as E. canadensis $[83,84]$. A comprehensive review of all the available information about Echinococcus species infecting dromedaries is needed to show which species occur more commonly in each region, continent and at global scale.

\section{Linguatulosis in camels}

Humans become infected with the cosmopolitan pentastomid Linguatula serrata by ingestion of eggs from the faeces of infected dogs or consumption of raw or undercooked infected viscera of intermediate ruminant hosts and camels [85]. Human nasopharyngeal infection by the so-called tongue-worm can affect the nasopharynx, throat, eyes, lymph nodes, nose, oral cavity, lungs and liver [85]. Reliable data on the rate and geographical range of the infection in dogs are unavailable and diagnosis is challenging as infections in dogs are often asymptomatic [86]. However, clinical linguatulosis is increasingly reported in pet and stray dogs worldwide [87] and zoonotic cases of $L$. serrata infection are recorded from several countries in Asia, Europe, Africa and the Americas [85]. In camels, infection with $L$. serrata larvae in the liver, lungs, spleen, mesenteric and mediastinal lymph nodes have been reported from Iran, Egypt and Sudan $[79,85]$. Although consumption of improperly cooked and raw liver of infected intermediate hosts are major sources of zoonotic infection, the actual sources of infection in human patients have not been documented sufficiently, and camels may play an important role in the epidemiology of human and canine linguatulosis.

\section{Trichinellosis in camels}

The genus Trichinella comprises nine species and three genotypes occurring in birds, reptiles and more than 150 domestic and wild mammalian species [88]. Some species within the genus cause a meat-borne zoonosis responsible for 5751 cases and five deaths per year [88]. Although human risk for trichinellosis has historically been linked to Trichinella spiralis acquired from domestic pig or wild boar, meat of other omnivorous or carnivorous animals, but also from herbivorous domestic livestock and horses, have been implied in the occurrence of human trichinellosis [89]. Camelus sp. was listed as host of T. spiralis in India in 1977 [90], and as a sequel to a severe outbreak of trichinellosis in Germany attributed to spiced and dried camel meat, illegally imported from Cairo, a few confirming studies were conducted [91]. While, the camel origin of the exotic dish incriminated for that outbreak could not been confirmed, experimental infection of camels with T. spiralis from pork meat resulted in a high Trichinella burden of the smooth and striated muscles [92]. Based on these finding and on the fact that meat from sheep, cattle and horse has been recognized as source of human trichinellosis in several outbreaks [89], the role of camels in the epidemiology of trichinellosis needs further investigation. This should be a priority, also considering that eating raw camel meat is popular among camel nomads in some regions, and severe foodborne outbreaks of plague have occurred due to this habit [93].

\section{Zoonotic gastropod-borne trematodes in camels}

Diseases caused by gastropod-borne helminths are estimated to affect more than 300 million people worldwide [94]. Camels can potentially play a role in the maintenance and transmission of several gastropod-borne trematodes in areas where both parasites and hosts are present. Fasciolosis is a food- and water-borne disease caused by Fasciola hepatica and Fasciola gigantica liver flukes. Human fascioliasis is an important public health problem and is considered a highly neglected tropical disease with estimated 35 to 72 million people infected worldwide [95]. Infections of camels with both fluke species with prevalences of up to $15 \%$ have been recorded $[79,96]$. Meanwhile, reports of human infections with $D$. dendriticum flukes are increasing, mainly due to the expansion of arid areas and the increase in anthelmintic 
resistance [97]. Dicrocoeliosis in humans is poorly known and probably underestimated; however, infections have been reported from several countries [98] and many animal species, including camels, have been demonstrated to harbor fertile adult flukes and excrete eggs with their faeces $[99,100]$.

Schistosomiasis is an infectious disease that affects more than 230 million people worldwide [101]. Four Schistosoma species, Schistosoma bovis, Schistosoma mattheei, Schistosoma indicum and Schistosoma turkestanica (syn. Orientobilharzia turkestanicum, Ornithobilharzia turkestanicum), have been reported in camels [102-104]. Schistosoma bovis and S. mattheei have also been described in humans [105], as well as human cercarial dermatitis caused by $S$. turkestanica has been reported [106].

\section{Arthropods infesting camels}

Camels can be infested by a wide range of external parasites that irritate, injure or debilitate them [9]. Moreover, different ticks and flies are biological and mechanical vectors of several viruses, bacteria and parasites that can induce human infections [9]. Camel mange caused by Sarcoptes scabiei var. cameli is a major threat to camel health and production as it is extremely contagious [9]. It is considered second only to Surra in terms of losses in camels [107] and its transmission to humans, particularly camel attendants and riders, is well-known since ancient times [108]. Infestation of camels with ticks of the genera Rhipicephalus, Hyalomma, Dermacentor, Ixodes, Amblyomma, Argas, Otobius and Ornithodoros is often reported [9]. Almost all of the tick genera above encompass species of known or putative vectors for zoonotic pathogens [109]. For instance, viruses with zoonotic potential have been detected by molecular methods in ticks collected from camels, including Crimean-Congo hemorrhagic fever virus [110], Alkhurma hemorrhagic fever [111], Dhori virus and Sindbis virus [112], Kadam virus [113] and Toghoto virus [114]. In addition, some bacteria of public health importance such as Coxiella burnetii [115], Rickettsia spp. (R. aeschlimannii, R. africae, R. sibirica mongolitimonae), Bartonella (B. bovis and B. rochalimae), Anaplasma phagocytophilum and Borrelia burgdorferi (s.l.) [116] have been detected in the blood of camels and/or ticks parasitizing them.

As Yersinia pestis has been isolated from Xenopsylla cheopis rat fleas captured near camel corrals [50] it has been assumed that they may act as vectors for plague in camels, which in turn, can infect humans directly or carry infected fleas close to humans. Infection of camels with plague has been suspected for a long time [117], and the role of this animal species in outbreaks in different countries have been documented although infection might show no overt symptoms [118]. Transmission of plague form camels to humans has been reported in Kazakhstan, where from 1907 to 2001, human plague was acquired from camels in 400 instances [119].

\section{Parasites of camels in Australia}

There is controversy about the estimated population of feral dromedary camels in Australia with an estimated number of between 300,000-1,200,000 camels [5, 120]. However, in-depth information about diseases of camels in Australia is scarce. In the only study available [121], cystic echinococcosis was reported with zero cases in 4915 camels examined during meat inspection in abattoirs. According to the current knowledge, the most common parasites of camels in Australia are Sarcoptes scabiei, B. coli and camel nasal bot fly, Cephalopina titillator, whereas Trichuris tenuis, Camelostrongylus mentulatus, Cooperia pectinata, Nematodirella dromedarii, Haemonchus sp., Trichostrongylus sp., Cooperia sp., Nematodirus sp., Nematodirella sp. and Eimeria cameli are less common. Cryptosporidium parvum was reported from a dromedary calf. Tapeworm infections and taeniid cysts were absent. Trypanosoma evansi was imported into Western Australia in 1907 with camels but was diagnosed and quickly eradicated before spreading [13, 67, 122-124]. Of the parasites listed, S. scabiei, C. parvum and $B$. coli are zoonotic.

In recent years, export of live camels from Australia to the Middle East has increased [125]. Apart from animal welfare issues, and possible intolerance of Australian camels to the climate of the Persian Gulf, the trade of animals on a global scale has implications for parasite spread. Recently it was suggested that treatment of internal parasites in livestock in the country of origin may help in preventing entrance of helminths to barns, flocks and pastures in the country of destination [126]. Since not much is known about the parasite fauna of Australian camels it is conceivable that certain parasite species are transferred to areas of the Middle East where they are currently absent. Conversely, the susceptibility of feral camels from Australia to the diverse parasite fauna of the Middle East upon their arrival remains to be discussed.

\section{Conclusions}

Due to their increasing importance as a livestock animal in marginal, desert areas of developing countries, the role of camels in the epidemiology of zoonotic parasitic infections needs to be further investigated, especially in view of the risk factors associated with them. So far, research on parasites of camels has focused on case reports or prevalence surveys by microscopical examination of faecal samples or blood smears [21, 127, 128], whereas identification of parasites by molecular 
tools and phylogenetic analyses are scarce. Considering this, it would be important to perform molecular investigations on parasites of camels and of people having direct contact to them, in order to improve the current understanding of transmission dynamics in epidemiological studies. In addition, the role of camels as hosts for zoonotic pathogens such as Trichinella needs confirmatory evidence, and further studies of infectivity, pathogenicity, muscle larvae distribution and antibody development are necessary to understand the role of camels in the maintenance, distribution and transmission of this parasite. As a large portion of the camel population is kept in communities lacking equipment and trained personnel for carrying out parasitological examinations, there is a need for the development of rapid diagnostic tests for the detection of the most important camel parasites. Moreover, international and local organizations must work to increase the awareness of the zoonotic risk of camel parasites and the ways of pathogen transmission for people working in close contact with camels. Most importantly, the high risk of acquiring zoonotic infections by consumption of raw milk, meat and liver of infected camels, as well as their role in maintaining zoonotic transmission of hydatidosis must be communicated in the best possible way.

\section{Abbreviations}

OWC: old world camelids; NWC: new world camelids; MERS: Middle East respiratory syndrome; PCR: polymerase chain reaction; DALY: disability-adjusted life year; APOL1: apolipoprotein L1; CE: cystic echinococcosis.

\section{Acknowledgements}

This article was planned under the academic agreement between the Bu-Ali Sina University Hamedan (Iran) and the University of Bari (Italy).

\section{Authors' contributions}

AS, AJ and DO conceived the idea. AS wrote the manuscript and prepared an original draft. AJ and DO reviewed the manuscript. All authors read and approved the final manuscript.

\section{Funding}

Not applicable.

\section{Availability of data and materials}

All data generated or analyzed during this study are included in this published article.

\section{Ethics approval and consent to participate}

Not applicable.

\section{Consent for publication}

Not applicable.

\section{Competing interests}

The authors declare that they have no competing interests.

\section{Author details}

${ }^{1}$ Department of Pathobiology, Faculty of Veterinary Science, Bu-Ali Sina University, Hamedan 6517658978, Iran. ${ }^{2}$ Institute of Parasitology, Department of Pathobiology, University of Veterinary Medicine Vienna, Veterinaerplatz 1 ,
1210 Vienna, Austria. ${ }^{3}$ Department of Veterinary Medicine, University of Bari, Str. prov. per Casamassima km 3, 70010 Valenzano, Bari, Italy.

Received: 6 September 2019 Accepted: 19 December 2019

Published online: 27 December 2019

\section{References}

1. FAOSTAT. Food and Agriculture Organization of the United Nations Statistics Division. 2019. http://www.fao.org/faostat. Accessed 27 Oct 2019.

2. Sazmand A. Molecular identification of vector-borne parasites in blood of camels (Camelus dromedarius) of Iran. Ph.D. thesis, University of Veterinary Medicine, Vienna; 2016.

3. Burger PA. The history of Old World camelids in the light of molecular genetics. Trop Anim Health Prod. 2016;48:905-13.

4. MacHugh DE, Larson G, Orlando L. Taming the past: ancient DNA and the study of animal domestication. Ann Rev Anim Biosci. 2017:5:329-51.

5. Camel-Scan: Large populations of feral camels in Australia. 2019. https ://www.feralscan.org.au/camelscan/default.aspx. Accessed 27 Oct 2019.

6. Ouajd S, Kamel B. Physiological particularities of dromedary (Camelus dromedarius) and experimental implications. Scand J Lab Anim Sci. 2009;36:19-29.

7. Zhu S, Zimmerman D, Deem SL. A review of zoonotic pathogens of dromedary camels. EcoHealth. 2019;16:356-77.

8. Schuster RK. Parasites of dromedaries and bactrian camels - a review part 1: stenoxenous parasites. J Camel Pract Res. 2018;25:1-8.

9. Wernery U, Kinne J, Schuster RK. Camelid infectious disorders. Paris: World Organisation for Animal Health (OIE); 2014.

10. Ruggiero MA, Gordon DP, Orrell TM, Bailly N, Bourgoin T, Brusca RC, et al. Correction: a higher level classification of all living organisms. PLoS ONE. 2015;10(6):e0130114.

11. Dubey J, Schuster R. A review of coccidiosis in Old World camels. Vet Parasitol. 2018;262:75-83.

12. Sazmand A, Rasooli A, Nouri M, Hamidinejat H, Hekmatimoghaddam S. Prevalence of Cryptosporidium spp. in camels and involved people in Yazd Province, Iran. Iran J Parasitol. 2012;7:80-4.

13. Zahedi A, Lee GK, Greay TL, Walsh AL, Blignaut DJ, Ryan UM. First report of Cryptosporidium parvum in a dromedary camel calf from Western Australia. Acta Parasitol. 2018:63:422-7.

14. Ryan U, Hijjawi N, Xiao L. Foodborne cryptosporidiosis. Int J Parasitol. 2018:48:1-12

15. Feng Y, Ryan UM, Xiao L. Genetic diversity and population structure of Cryptosporidium. Trends Parasitol. 2018;34:997-1011.

16. Baroudi D, Zhang H, Amer S, Khelef D, Roellig DM, Wang Y, et al. Divergent Cryptosporidium parvum subtype and Enterocytozoon bieneusi genotypes in dromedary camels in Algeria. Parasitol Res. 2018;117:905-10.

17. Gu Y, Wang X, Zhou C, Li P, Xu Q, Zhao C, et al. Investigation on Cryptosporidium infections in wild animals in a zoo in Anhui Province. J Zoo Wildl Med. 2016:47:846-54.

18. El-Alfy ES, Abu-Elwafa S, Abbas I, Al-Araby M, Al-Kappany Y, Umeda $\mathrm{K}$, et al. Molecular screening approach to identify protozoan and trichostrongylid parasites infecting one-humped camels (Camelus dromedarius). Acta Trop. 2019;197:105060.

19. Lal A, Dobbins T, Bagheri N, Baker MG, French NP, Hales S. Cryptosporidiosis risk in New Zealand children under 5 years old is greatest in areas with high dairy cattle densities. EcoHealth. 2016;13:652-60.

20. Ryan U, Hijjawi N, Feng Y, Xiao L. Giardia: an under-reported foodborne parasite. Int J Parasitol. 2019;49:1-11.

21. Al-Jabr OA, Mohammed GE, Al-Hamdan BA. Giardiosis in camels (Camelus dromedarius). Vet Rec. 2005;157:350-2.

22. Cacciò SM, Lalle M, Svärd SG. Host specificity in the Giardia duodenalis species complex. Infect Genet Evol. 2018;66:335-45.

23. Schuster FL, Ramirez-Avila L. Current world status of Balantidium coli. Clin Microbiol Rev. 2008;21:626-38.

24. Cox FEG. Human balantidiasis in Iran: are camels reservoir hosts? Trends Parasitol. 2005;21:553 
25. Nakauchi K. The prevalence of Balantidium coli infection in fifty-six mammalian species. J Vet Med Sci. 1999;61:63-5.

26. Hegner R. Specificity in the genus Balantidium based on size and shape of body and macronucleus, with descriptions of six new species. Am J Epidemiol. 1934;19:38-67.

27. Khodakaram-Tafti A, Maleki M, Oryan A. Pathological study of intestines and mesentric lymph nodes of camels (Camelus dromedarius) slaughtered in Iran. J Camel Pract Res. 2001;8:209-13.

28. Taylor MA, Coop RL, Wall RL. Veterinary Parasitology. 4th ed. Oxford: Wiley Blackwell; 2016.

29. Pomajbíková K, Obornik M, Horák A, Petrželková KJ, Grim JN, Levecke $B$, et al. Novel insights into the genetic diversity of Balantidium and Balantidium-like cyst-forming ciliates. PLoS Negl Trop Dis. 2013;7:e2140.

30. Scanlan PD, Stensvold CR. Blastocystis: getting to grips with our guileful guest. Trends Parasitol. 2013;29:523-9.

31. Lepczyńska M, Białkowska J, Dzika E, Piskorz-Ogórek K, Korycińska J. Blastocystis: how do specific diets and human gut microbiota affect its development and pathogenicity? Eur J Clin Microbiol Infect Dis. 2017;36:1531-40.

32. Stenzel D, Cassidy M, Boreham P. Morphology of Blastocystis sp. isolated from circus animals. Int J Parasitol. 1993;23:685-7.

33. Alfellani MA, Taner-Mulla D, Jacob AS, Imeede CA, Yoshikawa H, Stensvold CR, et al. Genetic diversity of Blastocystis in livestock and zoo animals. Protist. 2013;164:497-509.

34. Mokhtar A, Youssef A. Subtype analysis of Blastocystis sppisolated from domestic mammals and poultry and its relation to transmission to their in-contact humans in Ismailia governorate, Egypt. Parasitol Unit J. 2018;11:90-8

35. Li W, Feng Y, Santin M. Host specificity of Enterocytozoon bieneusi and public health implications. Trends Parasitol. 2019;35:436-51.

36. Matos O, Lobo ML, Xiao L. Epidemiology of Enterocytozoon bieneusi infection in humans. J Parasitol Res. 2012;2012:981424.

37. Djurković-Djaković O, Dupouy-Camet J, Van der Giessen J, Dubey JP. Toxoplasmosis: overview from a one health perspective. Food Waterborne Parasitol. 2019;12:e00054.

38. Bahia-Oliveira L, Gomez-Marin J, Shapiro K. Toxoplasma gondii. In: Rose JB, Jiménez-Cisneros B. Global water pathogen project; 2017. http:// www.waterpathogensorg/book/toxoplasma-gondii. Accessed 27 Oct 2019

39. Scallan E, Hoekstra R, Mahon B, Jones T, Griffin P. An assessment of the human health impact of seven leading foodborne pathogens in the United States using disability adjusted life years. Epidemiol Infect. 2015;143:2795-804.

40. Scallan E, Hoekstra RM, Angulo FJ, Tauxe RV, Widdowson MA, Roy SL, et al. Foodborne illness acquired in the United States-major pathogens. Emerg Infect Dis. 2011;17:7-15.

41. Hamidinejat H, Ghorbanpour M, Rasooli A, Nouri M, Hekmatimoghaddam S, Mohammad Namavari M, et al. Occurrence of anti-Toxoplasma gondii and Neospora caninum antibodies in camels (Camelus dromedarius) in the center of Iran. Turk J Vet Anim Sci. 2013;37:277-81.

42. Dubey JP. Toxoplasmosis of animals and humans. Boca Raton: CRC Press; 2010

43. Gebremedhin EZ, Yunus HA, Tesfamaryam G, Tessema TS, Dawo F, Terefe $\mathrm{G}$, et al. First report of Toxoplasma gondii in camels (Camelus dromedarius) in Ethiopia: bioassay and seroepidemiological investigation. BMC Vet Res. 2014;10:222

44. Tonouhewa ABN, Akpo Y, Sessou P, Adoligbe C, Yessinou E, Hounmanou YG, et al. Toxoplasma gondii infection in meat animals from Africa: systematic review and meta-analysis of sero-epidemiological studies. Vet World. 2017:10:194.

45. Khamesipour F, Doosti A, Iranpour Mobarakeh H, Komba EVG. Toxoplasma gondii in cattle, camels and sheep in Isfahan and Chaharmaha va Bakhtiary Provinces, Iran. Jundishapur J Microbiol. 2014;7:e17460.

46. Hagemoser W, Dubey J, Thompson J. Acute toxoplasmosis in a camel. J Am Vet Med Assoc. 1990;196:347.

47. Riley J, Garner MM, Kiupel M, Hammond EE. Disseminated toxoplasmosis in a captive adult dromedary camel (Camelus dromedarius). J Zoo Wildl Med. 2017;48:937-40.

48. Ishag MY, Majid A. Association of diarrhea with congenital toxoplasmosis in calf-camel (Camelus dromedarius). Int J Trop Med. 2008;3:10-1.
49. Ishag MY. Studies on Toxoplasma and Sarcocystis from camels (Camelus dromedaries) in the Sudan. Ph.D. thesis, University of Khartoum; 2003.

50. Saeed AAB, Al-Hamdan NA, Fontaine RE. Plague from eating raw camel liver. Emerg Infect Dis. 2005;11:1456-7.

51. Belluco S, Mancin M, Conficoni D, Simonato G, Pietrobelli M, Ricc A. Investigating the determinants of Toxoplasma gondii prevalence in meat: a systematic review and meta-regression. PLoS ONE. 2016;11:e0153856.

52. Boughattas S. Toxoplasma infection and milk consumption: metaanalysis of assumptions and evidences. Crit Rev Food Sci Nutr. 2017:57:2924-33.

53. Medani M, Mohamed H. Camel's milk as a source of human toxoplasmosis in Butana area-Sudan. Int J Infect Dis. 2016;45:471-2.

54. Elfadaly HA, Hassanan N, Shaapan RM, Hassanain MA, Barakat AM, Abdelrahman KA. Molecular detection and genotyping of Toxoplasma gondii from Egyptian isolates. Asian J Epidemiol. 2017;10:37-44.

55. Tavakoli Kareshk A, Tavakoli Oliaee R, Mahmoudvand H, Keyhani A, Mohammadi MA, Bamorovat $\mathrm{M}$, et al. The first survey of isolation and molecular typing of Toxoplasma gondii by bioassay and PCR method in BALB/C mice in camels from eastern Iran. Iran J Parasitol. 2018;13:382-91.

56. Ajzenberg D, Yera H, Marty P, Paris L, Dalle F, Menotti J, et al. Genotype of 88 Toxoplasma gondii isolates associated with toxoplasmosis in immunocompromised patients and correlation with clinical findings. J Infect Dis. 2009;199:1155-67.

57. Shwab EK, Zhu X-Q, Majumdar D, Pena HF, Gennari SM, Dubey JP, et al. Geographical patterns of Toxoplasma gondii genetic diversity revealed by multilocus PCR-RFLP genotyping. Parasitology. 2014;141:453-61.

58. Roettcher D, Schillinger D, Zweygarth E. Trypanosomiasis in the camel (Camelus dromedarius). Rev Sci Tech. 1987;6:463-70.

59. Desquesnes M, Holzmuller P, Lai D-H, Dargantes A, Lun Z-R, Jittaplapong S. Trypanosoma evansi and surra: a review and perspectives on origin, history, distribution, taxonomy, morphology, hosts, and pathogenic effects. Biomed Res Int. 2013;2013:194176.

60. Dirie MF, Wallbanks K, Aden AA, Bornstein S, Ibrahim M. Camel trypanosomiasis and its vectors in Somalia. Vet Parasitol. 1989;32:285-91.

61. Birhanu H, Fikru R, Said M, Kidane W, Gebrehiwot T, Hagos A, et al. Epidemiology of Trypanosoma evansi and Trypanosoma vivax in domestic animals from selected districts of Tigray and Afar regions, northern Ethiopia. Parasites Vectors. 2015;8:212

62. Lai D-H, Hashimi H, Lun Z-R, Ayala FJ, Lukes J. Adaptations of Trypanosoma brucei to gradual loss of kinetoplast DNA: Trypanosoma equiperdum and Trypanosoma evansi are petite mutants of T. brucei. Proc Natl Acad Sci USA. 2008;105:1999-2004.

63. Aregawi WG, Agga GE, Abdi RD, Büscher P. Systematic review and meta-analysis on the global distribution, host range, and prevalence of Trypanosoma evansi. Parasites Vectors. 2019;12:67.

64. Gutierrez C, Desquesnes M, Touratier L, Büscher P. Trypanosoma evansi: recent outbreaks in Europe. Vet Parasitol. 2010;174:26-9.

65. Sazmand A, Eigner B, Mirzaei M, Hekmatimoghaddam S, Harl J, Duscher GG, et al. Molecular identification of hemoprotozoan parasites in camels (Camelus dromedarius) of Iran. Iran J Parasitol. 2016;11:568-73.

66. Clarence-Smith WG. The historical spread of Trypanosoma evansi (surra) in camels: a factor in the weakening of Islam? In: Emery E, editor. Selected papers from the first international conference of camel cultures: historical traditions, present threats and future prospects. London: RN Books; 2013. p. 87-94.

67. Reid SA. Trypanosoma evansi control and containment in Australasia. Trends Parasitol. 2002;18:219-24.

68. Truc P, Büscher P, Cuny G, Gonzatti MI, Jannin J, Joshi P, et al. Atypical human infections by animal trypanosomes. PLoS Negl Trop Dis. 2013;7:e2256

69. Joshi PP, Shegokar VR, Powar RM, Herder S, Katti R, Salkar HR, et al. Human trypanosomiasis caused by Trypanosoma evansi in India: the first case report. Am J Trop Med Hyg. 2005;73:491-5.

70. Van Vinh Chau L, Buu Chau L, Desquesnes M, Herder S, Phu Huong Lan $\mathrm{N}$, Campbell Jl, et al. A clinical and epidemiological investigation of the first reported human infection with the zoonotic parasite Trypanosoma evansi in Southeast Asia. Clin Infect Dis. 2016:62:1002-8. 
71. Vanhollebeke B, Truc P, Poelvoorde P, Pays A, Joshi PP, Katti R, et al. Human Trypanosoma evansi infection linked to a lack of Apolipoprotein L-I. N Eng J Med. 2006;355:2752-6.

72. Antoine-Moussiaux N, Desmecht D. Epidémiologie de l'infection par Trypanosoma evansi. Ann Méd Vét. 2008;152:191-201.

73. Luckins A. Epidemiology of surra: unanswered questions. J Protozool Res. 1998:8:106-19.

74. Oyieke F, Reid G. The mechanical transmission of Trypanosoma evansi by Haematobia minuta (Diptera: Muscidae) and Hippobosca camelina (Diptera: Hippoboscidae) from an infected camel to a mouse and the survival of trypanosomes in fly mouthparts and gut. Folia Vet. 2003:47:38-41.

75. Odeniran P, Macleod E, Ademola I, Welburn S. Molecular identification of bloodmeal sources and trypanosomes in Glossina spp., Tabanus spp. and Stomoxys spp. trapped on cattle farm settlements in southwest Nigeria. Med Vet Entomol. 2019;33:269-81.

76. Sadjjadi SM. Present situation of echinococcosis in the Middle East and Arabic North Africa. Parasitol Int. 2006:55:S197-202.

77. Fasihi Harandi M, Budke CM, Rostami S. The monetary burden of cystic echinococcosis in Iran. PLoS Negl Trop Dis. 2012;6:e1915.

78. Ebrahimpour M, Sadjjadi SM, Yousefi Darani H, Najjari M. Molecular studies on cystic echinococcosis of camel (Camelus dromedarius) and report of Echinococcus ortleppi in Iran. Iran J Parasitol. 2017;12:323-31.

79. Sazmand A, Joachim A. Parasitic diseases of camels in Iran (19312017) — a literature review. Parasite. 2017;24:21.

80. Deplazes P, Rinaldi L, Rojas CA, Torgerson P, Fasihi Harandi M, Romig T, et al. Global distribution of alveolar and cystic echinococcosis. Adv Parasitol. 2017;95:315-493.

81. Khademvatan S, Majidiani H, Foroutan M, Hazrati Tappeh K, Aryamand $\mathrm{S}$, Khalkhali $\mathrm{H}$. Echinococcus granulosus genotypes in Iran: a systematic review. J Helminthol. 2019;93(2):131-8.

82. Tigre W, Deresa B, Haile A, Gabriël S, Victor B, Van Pelt J, et al. Molecular characterization of Echinococcus granulosus s.l. cysts from cattle, camels, goats and pigs in Ethiopia. Vet Parasitol. 2016;215:17-21.

83. Ohiolei JA, Yan H-B, Li L, Magaji AA, Luka J, Zhu G-Q, et al. Cystic echinococcosis in Nigeria: first insight into the genotypes of Echinococcus granulosus in animals. Parasites Vectors. 2019;12:392.

84. AlKitani FA, Baqir S, Mansoor MK, AlRiyami S, Hussain MH, Roberts D. Genetic survey of cystic echinococcosis in farm animals in Oman. Trop Anim Health Prod. 2019. https://doi.org/10.1007/s11250-019-02019-5.

85. Hajipour N, Tavassoli M. Prevalence and associated risk factors of Linguatula serrata infection in definitive and intermediate hosts in Iran and other countries: a systematic review. Vet Parasitol Reg Stud Rep. 2019;16:100288

86. Otranto D. Diagnostic challenges and the unwritten stories of dog and cat parasites. Vet Parasitol. 2015;212:54-61.

87. Nagamori Y, Ramachandran A, Kuzma C, Nafe L, Johnson EM. A zoonotic parasite, Linguatula serrata, infection in a dog imported from Ethiopia to the United States. Vet Parasitol Reg Stud Rep. 2019;16:100273.

88. Devleesschauwer B, Praet N, Speybroeck N, Torgerson PR, Haagsma JA, De Smet K, et al. The low global burden of trichinellosis: evidence and implications. Int J Parasitol. 2015;45:95-9.

89. Rostami A, Gamble HR, Dupouy-Camet J, Khazan H, Bruschi F. Meat sources of infection for outbreaks of human trichinellosis. Food Microbiol. 2017;64:65-71.

90. Chaturvedi Y, Kansal KC. Check-list of Indian nematodes (animal parasites). Delhi: Controller of Publications; 1977.

91. Bommer W, Kaiser H, Mergerian H, Pottkämper G. Outbreak of trichinelliasis in a youth centre in Neidersachsen by air-dried imported camel meat. In: Proceedings of the 1st world congress on food-borne infections and intoxications. West Berlin, Germany; 1980. p. 441-4.

92. Eckhardt T, Abd-El-Rahman MS, Omar HM. Survey on the Trichinella larvae in butcher's meat offered in Cairoan shops. First experimental Trichinella infection in camel. In: 9th international symposium of world association of veterinary food hygienists, Budapest, Hungary; 1985. p. 139

93. Arbaji A, Kharabsheh S, Al-Azab S, Al-Kayed M, Amr Z, Abu Baker M, et al. A 12-case outbreak of pharyngeal plague following the consumption of camel meat, in north-eastern Jordan. Ann Trop Med Parasitol. 2005:99:789-93.
94. Giannelli A, Cantacessi C, Colella V, Dantas-Torres F, Otranto D. Gastropod-borne helminths: a look at the snail-parasite interplay. Trends Parasitol. 2016:32:255-64.

95. Sabourin E, Alda P, Vázquez A, Hurtrez-Boussès S, Vittecoq M. Impact of human activities on fasciolosis transmission. Trends Parasitol. 2018;34:891-903.

96. Banaja AA, Ghandour AM. A review of parasites of camels (Camelus dromedarius) in Saudi Arabia. J King Abdulaziz Univ. 1994;6:75-86.

97. Otranto D, Traversa D. Dicrocoeliosis of ruminants: a little known fluke disease. Trends Parasitol. 2003;19:12-5.

98. Mas-Coma S, Bargues M. Human liver flukes: a review. Res Rev Parasitol. 1997:57:145-218.

99. Cirak V, Senlik B, Gulegen E. Gastrointestinal parasites of camels (Camelus dromedarius) from turkey and efficacy of doramectin against trichostrongyles. J Camel Pract Res. 2011;18:283-5.

100. Asadov S. Analysis of the helminth fauna of the dromedary (Camelus dromedarius L 1758) in Azerbaidzhán. Dokl Akad Nauk Azerb SSR. 1957;13:781-4

101. Colley DG, Bustinduy AL, Secor WE, King CH. Human schistosomiasis. Lancet. 2014;383:2253-64.

102. Arfaa F, Sabaghian H, Ale-Dawood H. Studies on Ornithobilharzia turkestanicum (Skrjabin, 1913), Price, 1929 in Iran. Ann Parasitol Hum Comp. 1965;40:45-50.

103. Graber M, Tabo R, Service J. Enquêtes sur les helminthes du dromadaire tchadien: étude des strongyloses gastro-intestinales et de I'haemoncose à Haemoncus longistipes. Rev Elev Med Vet Pays Trop. 1967;20:227-54.

104. Chauhan A, Srivastava C, Chauhan B. Studies on the trematode fauna of India. Part 6. Digenea: Schistosomatidae - a monographic aid to the identification of Indian schistosomes. J Zool Soc India. 1973;25:83-127.

105. Cox FE. Taxonomy and classification of human parasitic protozoa and helminths. Manual of clinical microbiology. 11th ed. Washington: American Society of Microbiology; 2015. p. 2285-92.

106. Sahba GH, Malek EA. Dermatitis caused by cercariae of Orientobilharzia turkestanicum in the Caspian Sea area of Iran. Am J Trop Med Hyg. 1979;28:912-3.

107. Pegram R, Higgins AJ. Camel ectoparasites: a review. In: Allen W, Higgins A, Mayhew I, Snow D, Wade J, editors. Proceeding of the First International Camel Conference. Dubai: R\&W Publications (New Market); 1992. p. 69-78.

108. Tadjbakhsh H. Traditional methods used for controlling animal diseases in Iran. Rev Sci Tech. 1994:13:599-614.

109. Dantas-Torres F, Chomel BB, Otranto D. Ticks and tick-borne diseases: a one health perspective. Trends Parasitol. 2012;28:437-46.

110. Champour M, Chinikar S, Mohammadi G, Razmi G, Shah-Hosseini $\mathrm{N}$, Khakifirouz S, et al. Molecular epidemiology of Crimean-Congo hemorrhagic fever virus detected from ticks of one humped camels (Camelus dromedarius) population in northeastern Iran. J Parasites Dis. 2016:40:110-5.

111. Charrel RN, Fagbo S, Moureau G, Alqahtani MH, Temmam S, De Lamballerie X. Alkhurma hemorrhagic fever virus in Ornithodoros savignyi ticks. Emerg Infect Dis. 2007;13:153.

112. Al-Khalifa MS, Diab FM, Khalil GM. Man-threatening viruses isolated from ticks in Saudi Arabia. Saudi Med J. 2007;28:1864-7.

113. Wood OL, Moussa MI, Hoogstraal H, Büttiker W. Kadam virus (Togaviridae, Flavivirus) infecting camel-parasitizing Hyalomma dromedarii ticks (Acari: Ixodidae) in Saudi Arabia. J Med Entomol. 1982;19:207-8.

114. Williams R, Hoogstraal H, Casals J, Kaiser M, Moussa M. Isolation of Wanowrie, Thogoto, and Dhori viruses from Hyalomma ticks infesting camels in Egypt. J Med Entomol. 1973;10:143-6.

115. Loftis AD, Reeves WK, Szumlas DE, Abbassy MM, Helmy IM, Moriarity $J R$, et al. Rickettsial agents in Egyptian ticks collected from domestic animals. Exp Appl Acarol. 2006;40:67-81.

116. Sazmand A, Harl J, Eigner B, Hodžić A, Beck R, Hekmatimoghaddam S, et al. Vector-borne bacteria in blood of camels in Iran: new data and literature review. Comp Immunol Microbiol Infect Dis. 2019;65:48-53.

117. Fedorov V. Plague in camels and its prevention in the USSR. Bull World Health Organ. 1960;23:275-81.

118. Stenseth NC, Atshabar BB, Begon M, Belmain SR, Bertherat E, Carniel E, et al. Plague: past, present, and future. PLoS Med. 2008;5:e3. 
119. Aikimbayew A, Meka-Mechenko T, Temiralieva G, Bekenov J, Sagiyev Z, Kaljan K, et al. Plague peculiarities in Kazakhstan at the present time. Przeg Epidemiol. 2003;57:593-8.

120. McGregor M, Hart Q, Bubb A, Davies R. Managing the impacts of feral camels across remote Australia: final report of the Australian Feral Camel Management Project. Ninti One Limited; 2013. https://www.ninti one.com.au/resource/ManaginglmpactsFeralCamels_FinalReportAFCM P.pdf. Accessed 27 Oct 2019.

121. Brown A. A review of camel diseases in central Australia. Department of Business, Industry and Resource Development; 2004. https://dpir. nt.gov.au/_data/assets/pdf_file/0014/233222/tb314.pdf. Accessed 27 Oct 2019

122. Beveridge I, Green P. Species of Trichuris in domestic ruminants in Australia. Aust Vet J. 1981;57:141-2.

123. Beveridge I, Barker I, Rickard M, Burton J. Experimental infection of sheep with Camelostrongylus mentulatus and associated gastritis. Aust Vet J. 1974;50:36-7.

124. Barton M. Nasal and gastro-intestinal parasites of the camel (Camelus dromedarius) from Central Australia. T Royal Soc South Aust. 2008:132:40-2.
125. Australian Government. Camel coup for Ngaanyatjarra Camel Company. https://www.ilc.gov.au/ngaanyatjarracamels. 2017. Accessed 27 Oct 2019.

126. Sazmand A. International movement of livestock and lack of regulation for internal parasites monitoring. Iran J Parasitol. 2019;14:682-3.

127. Tajik J, Nourollahi Fard SR, Paidar A, Anousheh S, Dehghani E. Balantidiasis in a dromedarian camel. Asian Pac J Trop Dis. 2013;3:409-12.

128. Sazmand A, Rasooli A, Nouri M, Hamidinejat H, Hekmatimoghaddam S. Serobiochemical alternations in subclinically affected dromedary camels with Trypanosoma evansi in Iran. Pak Vet J. 2011;31:223-6.

\section{Publisher's Note}

Springer Nature remains neutral with regard to jurisdictional claims in published maps and institutional affiliations.

Ready to submit your research? Choose BMC and benefit from:

- fast, convenient online submission

- thorough peer review by experienced researchers in your field

- rapid publication on acceptance

- support for research data, including large and complex data types

- gold Open Access which fosters wider collaboration and increased citations

- maximum visibility for your research: over 100M website views per year

At BMC, research is always in progress.

Learn more biomedcentral.com/submissions 